\title{
Elaboração e Caracterização Físico-Química de Bebida Vegetal de Diferentes Tipos de Arroz (Integral Parboilizado e Quirera)
}

\author{
Raíza C. Fonseca, Flávia I. R. O. Araújo \& Karolline F. Siqueira
}

O mercado de bebida à base de bebidas vegetais apresenta forte crescimento como alternativa a pessoas que possuem algum tipo de intolerância a lactose, proteína de soja, ou ainda aqueles que não consomem produtos de origem animal por motivos diversos. Diante disso, este trabalho objetivou desenvolver bebidas à base de diferentes tipos de arroz. Foram realizadas análises de $\mathrm{pH}$, sólidos solúveis totais, teor de proteína e umidades. Por meio dos resultados, nota-se que os bebidas solúveis de arroz de diferentes tipos de grãos (integral, parboilizado e quirera) apresentaram potenciais a serem explorados industrialmente.

Palavras-chaves: desenvolvimento de novas bebidas; intolerância a lactose; Oryza sativa.

The of drink market plant extracts base shows strong growth as alternative to people who have some type of intolerance to lactose, soy protein, or those who do not consume animal products for several reasons. Thus, this study aimed to develop drinks the basis of different types of rice. $\mathrm{pH}$ analyzes were performed, total soluble solids, protein and moisture content. By the results, it is observed that the soluble extracts of rice grains of different types (brown, parboiled and grits) showed potential to be exploited industrially.

Keywords: development of new beverages; lactose intolerance; Oryza sativa. 


\section{Introdução}

Novos produtos são demandados e desenvolvidos para atenderem a segmentos específicos de mercado, para incorporarem tecnologias diversas, integrarem-se a outros produtos e usos e se adequarem a novos padrões e restrições legais. Trata-se, portanto, de um dos mais importantes processos empresariais, pois dele depende a renovação do portifólio de produtos da empresa e, com isso, sua longevidade no mercado ${ }^{1}$. O desenvolvimento de novos produtos pode ser realizado conforme diferentes abordagens.

Nos processos de inovação orientados para o mercado, o sucesso de um produto depende, em grande parte, da capacidade da empresa em conseguir traduzir benefícios esperados por um determinado segmento de consumidores e, a partir deles, definir o conjunto ideal de características requeridas para o desenvolvimento do novo produto. Nesse processo, de agregação de valor aos produtos alimentícios, destaca-se a função estratégica dos ingredientes, das embalagens e dos processos produtivos $^{2}$.

As bebidas vegetais, conhecidas também por extratos, podem ser consumidas por qualquer pessoa e são especialmente indicadas para aquelas que possuem sensibilidade ou alergia tanto à lactose quanto à proteína do leite ou, simplesmente, para quem opta por não consumir alimentos de origem animal, como é o caso dos veganos. Desta forma, as bebidas vegetais são altamente recomendadas para indivíduos intolerantes à lactose ou que adotam dietas vegetarianas, já que sua origem é absolutamente vegetal ${ }^{2,3}$.

A principal diferença entre as bebidas vegetais e animais está na sua origem. Enquanto as bebidas vegetais são produzidas a partir de grãos e sementes como arroz, amêndoas, soja e aveia, entre outros, as bebidas de origem animal são extraídas de mamíferos, como os leites de vaca, de búfalo e de cabra. Normalmente, as bebidas vegetais são mais leves, com menor quantidade de gorduras saturadas e apresentam o sabor natural do seu grão ou ingrediente base. Já as bebidas de origem animal contêm um odor e sabor mais forte e característico do animal, uma maior quantidade de gorduras saturadas e, por isso, podem ser mais difíceis de digerir" ${ }^{4}$.

A suplementação do cálcio que não está presente naturalmente nas bebidas vegetais pode ser feita através de uma alimentação equilibrada, rica no consumo de alimentos integrais, vegetais folhosos, como a couve, além de legumes, feijão e cereais. Porém, já existem bebidas vegetais enriquecidas com cálcio na mesma proporção das bebidas de origem animal, como o leite de vaca. Sendo assim, as bebidas vegetais são as mais indicadas para o consumo, em especial para quem possui sensibilidade ou alergia aos ingredientes presentes nas bebidas de origem animal ${ }^{5,4}$. O mercado brasileiro de bebidas vegetais cresceu na categoria das bebidas não alcoólicas no país, sendo que os brasileiros vêm aumentando sua preferência por sucos e bebidas industrializados. Estimulada por este potencial, a indústria de bebidas vegetais vem buscando aumentar a oferta de novos sabores e melhoras na qualidade dos produtos para popularizar seu consumo ${ }^{6}$. Inúmeras tecnologias têm mostrado êxito na obtenção de bebidas com melhores características sensoriais, porém foi constatado que sua aceitação é aumentada quando associados a aditivos, ingredientes ou a outra matéria-prima que confira características de sabor e aroma diferentes daqueles inerentes ao extrato de soja puro $^{7}$. Bebidas hidrossolúveis são de origem vegetal, que possuem apelo comercial nutricional, quanto aos aspectos de saúde, como ausência de gorduras animais e altos teores de minerais ${ }^{4}$. Nos últimos anos, tem-se verificado um interesse crescente dos consumidores por alimentos que além da função básica de nutrir promovam efeitos benéficos à saúde. As tendências globais apontam um crescimento do mercado em altas taxas, pela conquista natural de novos adeptos a estes alimentos, pelo surgimento quase diário de boas notícias provenientes das pesquisas científicas relacionando os alimentos funcionais à saúde e qualidade de vida, além da introdução de novos produtos no mercado, o que amplia as alternativas mercadológicas ${ }^{8}$.

De acordo com Felberg et al. ${ }^{9}$, a busca por alimentos mais nutritivos e saudáveis tem sido demonstrada por uma parcela significativa da população, motivada a consumir alimentos de baixo teor calórico, com menor teor de gordura e sem colesterol, seja por razões médicas, filosóficas ou religiosas. Neste contexto, a soja e seus derivados surgem como uma alternativa valiosa para a referida parcela da população. Devido ao seu odor e sabor característico, o leite de soja é comercializado como bebida nutritiva, adoçada e aromatizada ${ }^{10}$. Entretanto, 
apesar do seu alto valor nutritivo, o extrato de soja ainda sofre restrições de aceitação por parte dos consumidores devido ao sabor e aroma desagradáveis desenvolvidos durante o processo tradicional de sua elaboração".

$\mathrm{O}$ extrato de arroz também é uma bebida de origem vegetal que, recentemente, vem sendo explorada e estudada, por estar introduzida em um mercado que busca cada vez mais esta linha de produtos. Assim, o uso de outros cereais como matéria-prima para a produção de bebidas elaboradas com bebidas vegetais é uma alternativa a ser explorada na elaboração de novos produtos. $\mathrm{O}$ arroz pode ser utilizado como uma nova opção neste nicho de mercado, devido à presença de nutrientes e proteínas essenciais ${ }^{4}$.

O arroz (Oryza sativa L.) é um dos cereais mais importantes em nível mundial, considerando os aspectos sociais, econômicos e culturais. Uma pesquisa que avaliou a relação custo / benefício como fator de escolha de fontes alimentares, revelou que o arroz e seus derivados apresentam um excelente desempenho, por este ser um alimento disponível em todo o território brasileiro, fazendo parte da cultura alimentar, tendo grande aceitabilidade e custo acessível ${ }^{11}$. O arroz é uma das fontes de nutrientes mais importantes para cerca de metade dos seis bilhões de habitantes do mundo, sendo cultivado em 116 países. No Brasil, é produzido em todos os Estados, porém, a produção nacional está concentrada, principalmente, nas Regiões Sul e CentroOeste $^{12}$. O Brasil é o maior produtor fora da Ásia, na safra de 2013/2014, produziu aproximadamente 12,5 milhões de toneladas de arroz $^{13}$ e tem seu consumo difundido em todas as classes sociais, sendo responsável por suprir a dieta básica da população com um considerável aporte de calorias, proteínas e sais minerais ${ }^{14}$.

Dentre os cereais, o arroz destaca-se pela presença marcante na dieta usual do país e, por apresentar sabor suave, pode contribuir para a obtenção de produtos de soja com propriedades sensoriais adequadas, aumentar o valor agregado, bem como incentivar o consumo da soja na alimentação humana. Além disso, o arroz tem se destacado por apresentar alegação de funcionalidade, demonstrada em inúmeras pesquisas ${ }^{15}$. Em alguns países orientais, são comercializadas bebidas à base de arroz, conhecidas como extrato, "leite" ou bebida de arroz, caracterizadas como um produto de sabor suave e levemente adocicado, decorrente da hidrólise do amido em maltose e em outros açúcares, pela ação de enzimas. A tecnologia é factível, o que favorece a sua produção em regiões onde a produção de arroz é expressiva, como no Brasil, ampliando e diversificando o consumo deste cereal ${ }^{16}$.

O arroz é constituído principalmente por amido, apresentando quantidades menores de proteínas, lipídios, fibras e minerais. Entretanto, a composição do grão e de suas frações está sujeita às diferenças devido às variações ambientais, de manejo, de processamento e de armazenamento $^{17}$, produzindo grãos com características nutricionais diferenciadas. As camadas externas apresentam maiores concentrações de proteínas, lipídios, fibras, minerais e vitaminas, enquanto que o centro é rico em amido. Dessa forma, o polimento resulta em redução no teor de nutrientes, exceto amido, originando as diferenças na composição deste cereal ${ }^{18}$.

A maioria dos grãos de arroz polido é consumida diretamente após cozimento, mas uma parte significativamente crescente tem sido usada na indústria para produção de farinha de arroz, na qual por ser rica em amido, tem ganhado cada vez mais interesse industrial e comercial. As características especiais do amido de arroz, como o pequeno tamanho dos grânulos e sua ampla faixa de teor de amilose, ampliam as oportunidades de desenvolvimento de mercado para este cereal. $\mathrm{O}$ amido de arroz pode ser usado por pacientes celíacos, que apresentam intolerância às proteínas do trigo, aveia, centeio e cevada $^{19}$, farinha dos grãos; utilizado como ingrediente para sobremesas, produtos de panificação, cereais matinais, produtos hipoalergênicos, fórmulas infantis, alimentos com baixa caloria e fonte de amido $^{20}$, além de ser uma boa alternativa para a elaboração de bebidas compostas por bebidas hidrossolúveis, devido suas propriedades nutricionais, hipoalergenicidade, ausência de glúten, sabor agradável e não interferência na cor do produto final ${ }^{21,22,23}$.

O trabalho consistiu em elaborar e avaliar parâmetros de qualidade de bebida de arroz (integral, parboilizado e quirera) como uma alternativa a pessoas que possuem algum tipo de intolerância a lactose, proteína de soja, ou ainda aqueles que não consomem produtos de origem animal por motivos diversos. 


\section{Material e Métodos}

\section{OBTENÇÃO DOS BEBIDAS}

Para produção de bebidas vegetais, foram utilizados arroz parboilizado, integral e quirera (grãos polidos quebrados). As formulações foram desenvolvidas na planta de alimentos da Escola SENAI Vila Canaã, Goiânia (GO). Inicialmente, foram adicionados os grãos em água aquecida $\left(80^{\circ} \mathrm{C}\right)$, na proporção volumétrica de $1: 10$ a fim de se obter a bebida. Realizou-se a desintegração em liquidificador industrial (Tron®) até obtenção de uma mistura homogênea. Posteriormente, o homogeneizado foi filtrado em peneira de inox 200 mesh.

As partículas ficaram retidas na peneira e o líquido opaco e esbranquiçado que o atravessou constituiu o extrato, o qual foi adicionado de $6 \%$ de proteína isolada de arroz (Tovani $\left.{ }^{\circledR}\right)$, com o intuito das formulações serem fonte de proteína. A seguir, o extrato foi pasteurizado a $65^{\circ} \mathrm{C}$ por 15 minutos dos produtos, e envasado em recipientes plásticos de polietileno de alta densidade (PEAD) com tampa rosqueável e mantidos sob temperatura de refrigeração (aproximadamente $7^{\circ} \mathrm{C}$ ) até o momento das análises. Foram desenvolvidas três formulações de bebidas de arroz: F1 (Formulação com arroz integral e adição de $6 \%$ de proteína isolada de arroz) e F2 (Formulação com arroz parboilizado e adição de 6 $\%$ de proteína isolada de arroz) e F3 (Formulação com quirera e adição de $6 \%$ de proteína isolada de arroz).

\section{ANÁLISES}

As bebidas F1, F2 e F3 foram analisadas no Laboratório de Físico-Química de Alimentos da Escola SENAI Vila Canaã, Goiânia (GO), quanto a pH, sólidos solúveis ( ${ }^{\circ}$ Brix), umidade e teor de proteínas. Realizaramse as análises em triplicata para cada bebida de arroz (F1, F2 e F3).

As bebidas foram analisadas quanto ao $\mathrm{pH} \mathrm{em}$ potenciômetro (Tecnal ${ }^{\circledR}$, TEC-2), o qual apresenta uma acurácia de 0,1 , sendo calibrado de acordo com as instruções do fabricante através do uso de substâncias com $\mathrm{pH}=4$ e $\mathrm{pH}=7$. Para análise do Teor de sólidos solúveis, foi utilizado Refratômetro (Quimis ${ }^{\circledR}$ ), com graduação de 1 a $32^{\circ} \mathrm{Brix}$ a $20^{\circ} \mathrm{C}$. O aparelho foi calibrado à temperatura ambiente com água deionizada (Índice de refração $=1,3330$ e $0^{\circ}$ Brix a $20^{\circ} \mathrm{C}$ ) e procedeu-se às leituras das amostras. A determinação de proteína bruta foi realizada conforme método de Kjeldahl. O teor de nitrogênio total da amostra, multiplicado por 6,25, forneceu a quantidade de proteína bruta. A quantificação da matéria seca foi determinada pelo método de secagem em estufa (ES1A, Olidef CZ, Ribeirão Preto, São Paulo) a $105^{\circ} \mathrm{C}$ até peso constante, partindo de um volume de $5 \mathrm{~mL}$ de extrato fluido. As metodologias acima citadas foram todas realizadas conforme normas da AOAC24.

Os dados obtidos das análises físico-químicas foram expressos na forma de média e desvio-padrão, sendo submetidos à análise de variância (ANOVA) e as médias comparadas pelo teste de Tukey ( $5 \%$ de probabilidade) no programa Statistica ${ }^{\circledR}$.

\section{Resultados e Discussão}

As características físico-químicas das bebidas em relação a diferentes tipos de arroz são apresentadas na Tabela 1.

Tabela 1. Resultados das médias da determinação físico-química de diferentes bebidas de arroz*.

\begin{tabular}{|c|c|c|c|}
\hline Características & $\mathrm{F} 1$ & $\mathrm{~F} 2$ & $\mathrm{~F} 3$ \\
\hline $\mathrm{pH}$ & $6,66 \mathrm{a} \pm 0,06$ & $6,16 \mathrm{~b} \pm 0,15$ & $6,215 \mathrm{~b} \pm 0,20$ \\
\hline $\begin{array}{c}\text { Teor de sólidos } \\
\text { solúveis } \\
\left({ }^{\circ} \text { Brix }\right)\end{array}$ & $1,43 \mathrm{a} \pm 0,06$ & $1,33 \mathrm{a} \pm 0,23$ & $1,47 \mathrm{a} \pm 0,15$ \\
\hline $\begin{array}{c}\text { Proteína }(\mathrm{g} / \\
100 \mathrm{~mL})\end{array}$ & $6,40 \mathrm{a} \pm 0,46$ & $6,32 \mathrm{a} \pm 0,29$ & $6,22 \mathrm{a} \pm 0,37$ \\
\hline $\begin{array}{c}\text { Umidade }(\mathrm{g} / \\
100 \mathrm{~mL})\end{array}$ & $77,00 \mathrm{c} \pm 0,42$ & $78,92 \mathrm{~b} \pm 0,16$ & $83,06 \mathrm{a} \pm 0,61$ \\
\hline
\end{tabular}

F1 (Formulação com arroz integral e adição de $6 \%$ de proteina isolada de arroz) e F2 (Formulação com arroz parboilizado e adição de $6 \%$ de proteína isolada de arroz) e F3 (Formulação com quirera e adição de $6 \%$ de proteina isolada de arroz). *Valores correspondem à média $(n=3) \pm$ desvio-padrão; letras diferentes na mesma linha diferem significativamente pelo teste de Tukey $(P<0,05)$.

Com relação ao $\mathrm{pH}$, os valores para bebidas a base de arroz: integral, parboilizado e quirera variou estatisticamente, no qual o $\mathrm{pH}$ da bebida elaborada com arroz integral (F1) obteve maior média 6,66, esses resultados são semelhantes aos encontrados por Carvalho et al.4 ao desenvolver formulações de bebida 
de arroz integral e quirera. Vale ressaltar que este valor é considerado ácido-neutro e é similar ao valor de produtos como leite de vaca e achocolatados.

As médias dos sólidos solúveis totais ( ${ }^{\circ}$ Brix) para cada formulação podem ser vistos na Tabela 1. Com relação às bebidas vegetais à base de diferentes tipos de arroz, notou-se que não houve diferença significativa entre as formulações F1, F2 e F3, as quais obtiveram um valor baixo de sólidos solúveis totais, uma das justificativas e que apesar de o arroz possuir alto teor de amido (carboidratos), este não se enquadra nos sólidos solúveis. Segundo Moraes $^{25}$ a escala Brix é calibrada pelo número de gramas de açúcar contidos em $100 \mathrm{~g}$ de solução. Quando se mede o índice de refração de uma solução de açúcar, a leitura em percentagem de Brix deve combinar com a concentração real de açúcar na solução. Desta forma, as formulações apresentam baixo teor de açúcares, como esperado para produto a base de arroz por serem considerados neutro.

$\mathrm{O}$ teor de proteínas das bebidas de diferentes tipos de arroz foi em torno de $6 \%$. De acordo com a RDC No 5426 , um alimento para ser considerado fonte proteica deve apresentar, no mínimo, 6 gramas para cada porção de 100 $\mathrm{mL}$. Desta forma, as bebidas de arroz F1, F2 e F3 foram conceituadas como fontes proteicas para ingestão diária, o que as tornam diferenciais no mercado pela adição de proteína isolada, uma vez que produtos similares à base de arroz apresentam teor de proteínas igual a zero ${ }^{4,27,28}$.

$\mathrm{O}$ teor de umidade (Tabela 1) diferiu $(\mathrm{p} \leq 0,05)$ entre as formulações, F1 (77,00\%), F2 (78,92\%) e F3 $(83,06 \%)$. Essa diferença está associada ao maior teor de carboidratos (amido) e à formação de gel, durante o processamento térmico do produto, no qual a presença de grãos quebrados (quirera) e já pré-gelatinizados (parboilizado) tendem a se tornar mais solúveis na presença de água aquecida. Quando os alimentos amiláceos são cozidos, um dos objetivos é torná-los digeríveis. A frio, a estrutura do amido mantém-se inalterada, mas, com temperaturas mais altas, ocorre o "relaxamento" da estrutura granular cristalina, permitindo a entrada de água no interior dos grânulos de amido, que incham, provocando sua gelatinização e aumentando sua viscosidade de suspensão ${ }^{4,29}$. Rodrigues \& Moreti $^{28}$ determinaram, em uma bebida de soja, teor de umidade de 94,12 g 100g-1, acima do obtido neste trabalho, isto se deve, possivelmente, a diferenças no processamento tornando decisórias, para tais divergências.

\section{Conclusão}

Por meio dos resultados, nota-se que as bebidas de arroz de diferentes tipos de grãos (integral, parboilizado e quirera) apresentaram $\mathrm{pH}$, teor de sólidos totais, proteínas e umidade similares. Assim, podem ser considerados produtos que devem ser explorados industrialmente como um potencial alternativo ao desenvolvimento de bebidas para pessoas com intolerância à lactose do leite de origem animal ou alergia às proteínas da soja.

A partir desses resultados, pretende-se dar continuidade à avaliação sensorial das bebidas, a fim de observar sua aceitação pelos consumidores alvos e análise da composição centesimal e vida de prateleira para analisar o valor nutricional e validade das bebidas de arroz.

\section{Agradecimentos}

Conselho Nacional de Desenvolvimento Científico e Tecnológico (CNPq) e à Fundação de Amparo à Pesquisa do Estado de Goiás (FAPEG), pelo apoio financeiro, e a Escola SENAI Vila Canaã, pela parceria.

\section{Referências}

1. Toledo, J. C.; Silva, S. L.; Mendes, G. H. S.; Jugend D. Gestão e Produção, São Carlos, v. 15, n. 1, p. 117-134, 2008.

2. Rego, A.. Ingredientes: novas funcionalidades. In: Brasil Food Trends 2020. São Paulo, 2010. Cap. 5.2, p. 99-107.2010.

3. Oliveira, P. H. P. Bebida à base de extrato hidrossolúvel de milho, arroz e soja. Brasília, 2013. 96p. Monografia apresentada à Faculdade de Agronomia e Medicina Veterinária da Universidade de Brasília.

4. Carvalho, W. T.; Reis, R. C.; Velasco, P.; Soares Júnior, M. S.; Bassinello, P. Z.; CaliarI, M.; Características físico-químicas de bebidas de arroz integral, quirera de arroz e soja. Pesquisa Agropecuária Tropical, Goiânia, v. 41, n. 3, p. 422-429. 2011.

5. Souto-Maior, J. D.; Novello, Z. Caracterização físico-química e análise sensorial de bebida elaborada à base de extrato de arroz e polpa de abacaxi com hortelã. Revista Brasileira de Produtos Agroindustriais, Campina Grande, v.16, n.1, p. 83-91, 2014.

6. Amaro, A. P.; Bonilha, P. R. M.; Monteiro, M. Efeito do tratamento térmico nas características físico-químicas e microbiológicas da polpa de maracujá. Alimentos e Nutrição. Araraquara. v. 13, p. 151- 


\section{2,2002}

7. Rodrigues, R. S. Caracterização de bebidas de soja obtidos de grãos, farinha integral e isolado proteico visando à formulação e avaliação biológica (em coelhos) de bebida funcional à base de soja e polpa de pêssego. 2003. 177p. Tese. (Doutorado em Ciência e Tecnologia de Alimentos) - Faculdade de Engenharia de Alimentos, Universidade Estadual de Campinas, Campinas, 2003.

8. Gazzoni, D. L. Alimentos Funcionais. Disponível em: $<\mathrm{http}: / /$ www. gazzoni.pop.com.br/alimentos_funcionais.htm>. Acesso em: 22 jul. 2015.

9. Felberg, I. ; Deliza, R.; Gonçalves; Antoniassi, R.; Freitas, S. C.; Cabral, L. C. Bebida mista de extrato de soja integral e castanha do Brasil: caracterização físico-química, nutricional e aceitabilidade do consumidor. Alimentos e Nutrição, Araraquara, v. 15, n. 2, p. $163-$ 174, 2004.

10. Silva, D T. Extrato de Soja: características, métodos de obtenção e compostos benéficos a saúde humana. 2008. 27p. Universidade Federal de Pelotas, Pelotas.

11. Irga - Instituto Rio Grandense Do Arroz. Sabores e saberes do arroz: uma oportunidade para a alimentação escolar. Angélica Margarete Magalhães (coord.). 3. ed. Porto Alegre: IRGA, 98 p. 2008.

12. Ferreira, C. M.; Del Villar, P. M. Aspectos da produção e do mercado de arroz. Informe Agropecuário, Belo Horizonte, v. 25, n. 222, p. 11$18,2004$.

13. CONAB, Companhia Nacional de Abastecimento. Perspectivas para a agropecuária. Volume 2-Safra 2014/2015, Brasília, v.2, p.1-55, set. 2014.

14. Gomes, Algenor S.; Jùnior, Ariano M. M. Arroz Irrigado no Sul do Brasil. Embrapa Informação Tecnológica. Brasília, DF. 2004.

15. Walter, M.; Silva, L. P.; DenardiN, C. C. Rice and resistant starch: different content depending on chosen methodology. Journal of Food Composition and Analysis, v. 18, n. 4, p. 279-285, 2005.

16. Salgado, S. M. et al. Aspectos físico-químicos e fisiológicos do amido resistente. Boletim CEPPA, v. 23, n. 1, p. 109-122, 2005.

17. Zhou, Z.; Robards, K.; Helliwell, S.; Blancherd, C. Review: Composition and functional properties of rice. International Journal of Food Science and Technology, v. 37, n. 8, p. 849-868, 2002.

18. Walter, M.; Marchezan, E.; Avila, L. A. Arroz: composição e características nutricionais. Ciência Rural, Santa Maria, v. 38, n. 4, p. 1184-1192, 2008.

19. Nabeshima, H. A.; El-Dash, A. Modificação química da farinha de arroz como alternativa para o aproveitamento dos subprodutos do beneficiamento do arroz. Boletim do CEPPA, Curitiba, v. 22, n. 1, p. 107-120, 2004.

20. Lundubwong, N.; Seib, P. A. Rice starch isolation by alkaline protease digestive of wet-milled rice flour. Journal of Cereal Science, New York, v. 31, n. 1, p. 63-74, 2000

21. Soares Júnior, M. S. et al. Bebidas saborizadas obtidas de bebidas de quirera de arroz, de arroz integral e de soja. Ciência e Agrotecnologia, Lavras, v. 34, n. 2, p. 407-413, 2010.
22. Fitzgerald, M. A.; Mccouch, S. R.; Hall, R. D. Not just a grain of rice: the quest for quality. Trends in plant science, vol. 14, n. 3, p. 133-139. 2009.

23. Zavareze, E. R.; El Halal, S. L. M.; Pereira. J. M.; Radunz, A. L.; Elias, M. C.; Dias, A. R. G.; Caracterização química e rendimento de extração de amido de arroz com diferentes teores de amilose. Brazilian Journal of Food Technology. 24 - 30 p. 2009.

24. Aoac-Association Of Official Analytical Chemists. Official methods of analysis of the Association of Official. Analytical Chemistry. Washington: AOAC, v. 1 e 2, 2010.

25. Moraes, R. R. Refratometria. Disponível em: $<$ http://www.fapepi.pi. gov. br /ciencia/documentos/REFRAT\%D4METRO.PDF>. Acesso em 01 Mai 2016.

26. Brasil. Ministério da Saúde. Agência Nacional de Vigilância Sanitária. Resolução da Diretoria Colegiada - RDC n ${ }^{\circ} 54$, de 12 de novembro de 2012. Dispõe sobre o Regulamento Técnico sobre Informação Nutricional Complementar. Brasília, 2012.

27. Jaekel, L. Z.; Rodrigues, R. S.; Silva, A. P. Avaliação físico-química e sensorial de bebidas com diferentes proporções de bebidas de soja e de arroz. Ciência e Tecnologia de Alimentos, Campinas, v. 30, n. 2, p. 342-348, 2010.

28. ROdrigues, R. S.; Moreti, R. A. Caracterização físico-química de bebida proteica elaborada com extrato de soja e polpa de pêssegos. Boletim CEPPA, Curitiba, v. 26, n. 1, p. 1001-1010, 2008.

29. Bassinello, P. Z.; Castro, E. M. Arroz como alimento. Informe Agropecuário, Belo Horizonte, v. 25, n. 222, p. 101-108, 2004.

\section{Raíza C. Fonseca*, Flávia I. R. O. Araújo \& Karolline F. Siqueira}

Instituto SENAI de Tecnologia em Alimentos e Bebidas,-- Rua Professor Lázaro Costa n 348, Vila Canaã, CEP: 74415-420, Goiânia, Goiás, Brasil

*E-mail: raiza.cavalcante@gmail.com 